\title{
Isolation, Characterization and Structure-Activity Studies of Novel Brevinin-1 Peptides from the Skin of the Frog Clinotarsus curtipes
}

\author{
Parvin Abraham and K. Santhosh Kumar \\ Chemical Biology Laboratory, Rajiv Gandhi Centre for Biotechnology, Thiruvananthapuram, Kerala, India
}

\section{Introduction}

Antimicrobial peptides (AMPs) have attained enormous attention as a substituent of antibiotics recently. The very quick mode of action on microbial targets and the less probability of forming resistance by the bacterial strains against AMPs place these molecules superior to conventional antibiotics. Usually they are small peptides comprising 9-40 amino acid residues, rich in basic amino acids and thus owing a positive charge. They are electrostatically attracted towards the negatively charged membrane.

Of the variable sources of AMPs, amphibian skin is regarded as a major source. They are secreted by the granular glands and released to the skin surface upon different kind of stimuli including any microbial attack or predator attack. Herein, we describe the isolation, characterization and plausible mode of action of brevinin-1CTcu1-5 peptides.

\section{Results and Discussion}

Five novel brevinin peptides (Brevinin1 CTcu1-5) were identified from the skin secretion of the frog Clinotarsus curtipes, inhabiting in the Western Ghats region of Kerala, India (Figure 1) and their sequences are given in Table 1. They were antibacterial in nature with their MICs ranging from $6.25 \mathrm{ug} / \mathrm{mL}$ to $100 \mathrm{ug} / \mathrm{mL}$ and were hemolytic against RBCs (Table 2). The broad antibacterial property exhibited by these peptides make them excellent candidates for future peptide antibiotics. However, by proper chemical engineering/modifications the adverse hemolytic issue should be addressed.

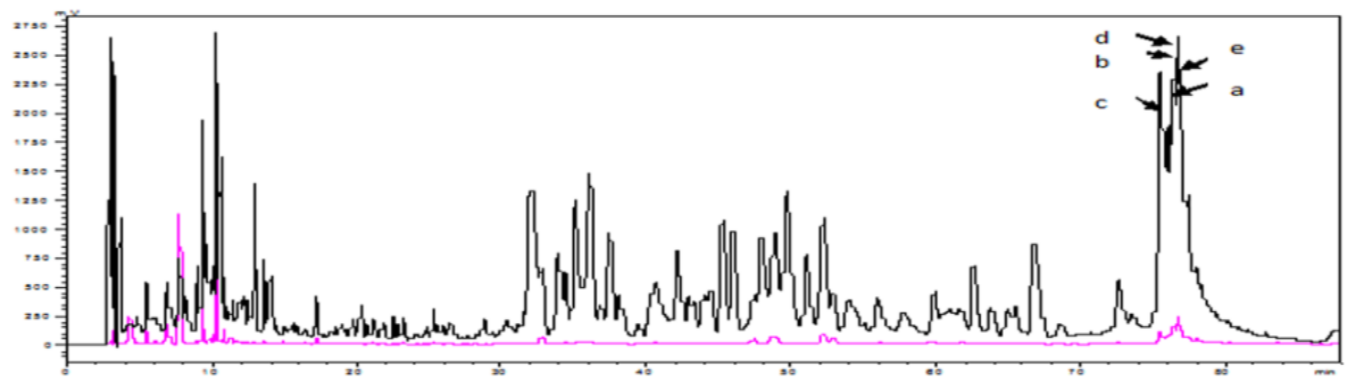

Fig. 1. RP-HPLC profile of the skin secretion of Clinotarsus curtipes.

Table 1. Primary Sequences of B1CTcul-5 peptides.

\begin{tabular}{ccccccc}
\hline Peptide & $\begin{array}{c}\text { No } \\
\text { AAs }\end{array}$ & Amino acid sequence & GRAVY & $\begin{array}{c}\text { Net } \\
\text { charge }\end{array}$ & $\begin{array}{c}\text { Calculated } \\
\text { mass (Da) }\end{array}$ & $\begin{array}{c}\text { Observed } \\
\text { mass (Da) }\end{array}$ \\
\hline B1CTcu1 & 19 & LIAGLAANFLPKLFCKITK & 1.042 & 3 & 2061.6 & 2061.6 \\
B1CTcu2 & 23 & FLPLLAGLAANFLPKIFCKITRK & 0.883 & 4 & 2575.2 & 2573.7 \\
B1CTcu3 & 22 & LPLLAGLAANFLPKIFCKITRK & 0.795 & 4 & 2428 & 2426.7 \\
B1CTcu4 & 23 & FLPFIAGMAAKFLPKIFCAISKK & 1.039 & 4 & 2542.2 & 2540.7 \\
B1CTcu5 & 21 & LIAGLAANFLPQILCKIARKC & 1.067 & 3 & 2256.8 & 2255.5 \\
\hline
\end{tabular}


The first step of the interaction of cationic peptides with bacterial membrane has been shown to involve negatively charged surface of the target cells. In gram negative bacteria, LPS in the outer membrane contribute significantly in this aspect. Dansyl polymyxin B displacement assay is used to quantify such kind of binding. Dansyl polymyxin B is a fluorescently tagged cationic lipopeptide, which fluoresces only when it binds to LPS and remain nonfluorescent in free solution. When the peptide binds to LPS, they displace dansyl polymyxin B, resulting in decreased fluorescence, which can be assessed as a function of peptide concentration as shown in Figure 2. The \% displacement was calculated relative to polymyxin B. From Figure 3, B1CTcu1-4 exhibited a steady increase in \% displacement with increase in peptide concentration. B1CTcu1-4 had more or less equal binding affinity with LPSs, but the relative binding or displacement capacity of B1CTcu5 was even lesser. Overall, in contrast to polymyxin B, the peptides had shown only a weak affinity with OM.

Table 2. Antimicrobial activity and \% hemolysis of B1CTcu1-5.

\begin{tabular}{llccccccc}
\hline \multicolumn{1}{c}{ E. coli } & V.cholerae & S.aureus & MRSA & B.subtilis & B.coagulans & VRE & \% hemo- \\
& \multirow{2}{*}{ MG1655 } & & MTCC & ATCC & 14416 & ATCC 7050 & ATCC & lysis \\
& & 9542 & 43300 & & & 29212 & \\
\hline B1 CTcu 1 & 8 & 12.5 & 12.5 & NA & $>25$ & 6.25 & NA & 1 \\
B1 CTcu 2 & 10 & 12.5 & 12.5 & 50 & 12.5 & 6.25 & 50 & 17.8 \\
B1 CTcu 3 & 6.25 & 12.5 & 6.25 & 50 & 12.5 & 6.25 & 100 & 45 \\
B1 CTcu 4 & 20 & 25 & 25 & $<6.25$ & 25 & NA & 25 & 54.8 \\
B1 CTcu 5 & 7 & 15 & NA & NA & $>200$ & 6.25 & NA & 37.5 \\
\hline
\end{tabular}

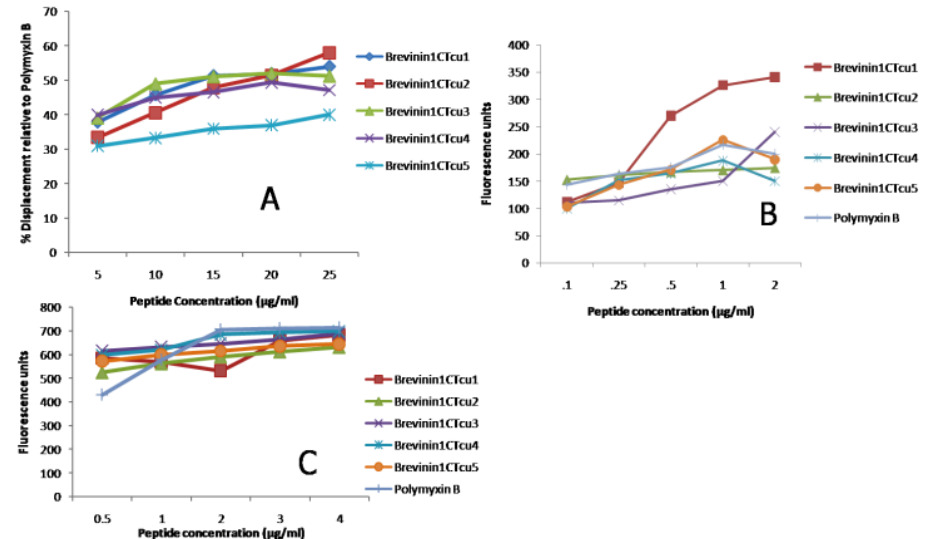

Fig 2. (A) Dansyl Polymyxin B displacement assay (B) NPN uptake assay (C) SYTOX green uptake assay.
NPN assay was conducted to determine whether the binding ability of the peptides with outer membrane correlate with its permeability [3]. The increase in the fluorescence indicate the peptide ability to permeabilise bacterial outer membrane. As shown in Figure 2, at a concentration well below the MIC itself, the peptides were able to permeabilise OM. There were differences in the degree of uptake of NPN, showing differences in the extent of membrane disruption among B1CTcu1-5. The potent B1CTcu1 exhibited highest OM permeabilisation efficiency compared to other peptides, including the positive control polymyxin. The fluorescence of SYTOX green increases drastically when it binds to intracellular nucleic acids. The extent of cytoplasmic membrane damage caused by the antimicrobial peptides can hence be studied by measuring the fluorescence produced by SYTOX green (Figure 2).

\section{References}

1. Zasloff, M. Nature 415, 389-395 (2000), http://dx.doi.org/10.1038/415389a

2. Hancock, R.E. The Lancet 349, 418-422 (1997), http://dx.doi.org/10.1016/S0140-6736(97)80051-7

3. Wu, M., Hancock, R.E. J. Biol. Chem. 274, 29-35 (1999), http://dx.doi.org/10.1074/jbc.274.1.29 